Kenneth Silver

Penultimate version

\title{
Group Action Without Group Minds
}

\begin{abstract}
Groups behave in a variety of ways. To show that this behavior amounts to action, it would be best to fit it into a general account of action. However, nearly every account from the philosophy of action requires the agent to have mental states such as beliefs, desires, and intentions. Unfortunately, theorists are divided over whether groups can instantiate these states-typically depending on whether or not they are willing to accept functionalism about the mind. But we can avoid this debate. I show how a more general view of action captures what is central to action without mentioning mental states, and I argue that a group's members can fulfill the role in group action that mental states play in our actions. Group behavior is explicable in terms of reasons, regardless of whether the group itself cognizes those reasons. After discussing the kind of reasons at issue and arguing that groups can act in light of them without minds, I assess how this account bears on the question of group responsibility.
\end{abstract}

We frequently speak as if there are groups and as if those groups can do things. A basketball team can win the championship; the Supreme Court can strike down the decision of a lower court; Amazon can acquire Whole Foods. One set of questions concerns whether there really are such groups and how best to understand their existence (as well as the differences between groups, collectives, corporations, etc.). Another kind of question, however, concerns whether the behavior of groups can appropriately be construed as actions. Here, I focus on the latter question.

Let's take it for granted that groups exist. ${ }^{1}$ Given this, there is a strong intuition that certain groups act. The acquisition of Whole Foods by Amazon is something done by Amazon that seems intelligible. It may follow from an overall market strategy, and management will point to this as the reason for the acquisition in answer to shareholder scrutiny. Even in cases of small groups, we readily ascribe actions. We would say, for example, that the tenure committee recommended tenure and had reasons for doing so.

To make good on this intuition, we need to see how the behavior of groups can be captured by a theory of action. There are many views of action that have been developed, so we would ideally need only to pick a good one and show how groups can satisfy its conditions. ${ }^{2}$ When trying to do this, though, what becomes apparent is that most of the prominent views of action in the literature involve

\footnotetext{
${ }^{1}$ We need only accept that some groups exist. This is not uncontroversial, but I take it for granted here and focus instead on whether what groups do can be construed as actions. See Ritchie (2013) for a discussion of a number of proposals of how groups exist, including her own. I remain agnostic here as to the nature of group existence. Though I am partial to an account on which groups are sui generis entities constituted by members in virtue of the group structure and certain social facts (bearing the most similarities to Uzquiano [2004]), the account of group action given here is compatible with different ways of reifying groups.

2 There are surprisingly few attempts of this kind in the literature. French (1979) is one exception, as he specifically models his view of corporate action on Davidson's views. In several places, Raimo Tuomela offers a view of group action. However, he does not embed group action into a more general account of action. For example, Tuomela (1989) understands group intentional action in terms of the intentional actions of their members, rather than in terms of a more general account of action. More common in the literature is a discussion of group agency, as opposed to group action. Rovane (1998), Copp (2006), Pettit (2007), and Pettit and List (2011) each focus on characterizing groups as agents, rather than showing directly how their conduct falls under a view of action. Assuming that it follows from S's being an agent that $\mathrm{S}$ can act, this would be a way of showing that groups act (although it would not tell us which of S's behaviors count as actions). My question is whether certain groups can perform actions, but I will briefly take up the question below of what further might need to be true in order for certain groups to count as responsible agents.
} 
Kenneth Silver

actions being caused or constituted by certain mental states. So, the possibility of group action will stand or fall depending on whether we accept group mental states and group minds. Insofar as a number of theorists have been willing to accept group minds, this approach may seem attractive. However, seeing this project through in a way that will satisfy opponents is more challenging than has been appreciated. Given this, I will chart a different course.

I start in the first section by showing how applying the most prominent accounts of action to the case of groups leads us to consider the possibility of group mentality. And whether one accepts group mentality tends to depend on whether one is willing to accept functionalism in the philosophy of mind. Unfortunately, opponents of group mentality are particularly unlikely to accept functionalism. Rather than taking a stand on this issue, I argue that a broader view of action should be accepted that does not require the agent to have mental states. For this account, what is crucial to action is that the agent is sensitive to its reasons. It may be that creatures like us are not able to satisfy this account without mental states, but I think that groups can, even if they do not have minds.

In the second section, I make good on this claim. The reasons central to my account are motivating reasons, so I argue that groups can act for motivating reasons. After making the prima facie case, I show how groups instantiate states that play the role that our mental states play in us. Our mental states allow us to appreciate and negotiate reasons, and they motivate us in light of them. Group behavior can be shown to be sensitive to considerations that bear on their behavior in just the same way, and this is facilitated by the group's members. This amounts to accepting a kind of functionalism about reason, and so I end the section by showing how functionalism about reasons is more easily accepted than functionalism about the mind. It's even a position to which a number of philosophers are already committed.

If the arguments are successful, then we will have a way of characterizing the behavior of many groups as actions without requiring those groups to instantiate mental states. Though this is the primary objective of the paper, many people thinking about this topic are concerned instrumentally; their real interest lies in the issue of group or collective responsibility. The question there is whether it is appropriate to hold groups morally responsible for what they do, or whether all of the responsibility of a group redounds to the members. In the third section, I consider how the view of group action advanced here bears on this question. One worry is that by accepting a view that does not require groups to have mental states, we have forfeited something necessary for them to be morally responsible. I show that this will not be the case on several different views of moral responsibility. This does not demonstrate that groups are morally responsible, and I acknowledge what remains to be shown in order to establish group responsibility. Still, defending a view of group action is an important step.

\section{From Group Behavior to Group Action}

Beginning only with the assumptions that certain groups exist and can be described as doing things, it is not difficult to argue that what groups do can amount to behavior. Dretske (1988) characterized the behavior of some entity as movement (or something done) that is caused by an event internal to the entity. Judging which processes are 'internal' to some entity can be difficult, perhaps especially for structured organizations like corporations. ${ }^{3}$ Still, whether we are talking in terms of the members of a

\footnotetext{
${ }^{3}$ Some of the challenge here may concern questions about the location of such entities and their relations to material parts. For discussion of the embodiment of the somehow related phenomena of 'establishments', see Korman (2020). This question of what is internal to a group is taken up further in section 2.1 .
} 
Kenneth Silver

group, or the systems/mechanisms through which the group operates, it is not hard to imagine an opponent of group action being brought along far enough to at least admit that certain groups behave in a myriad of ways. The question is whether any of this behavior is appropriately characterized as action. $^{4}$

To answer this, it would be ideal to have a truly general theory of action. Then, we could check to see whether the behavior of groups falls within the theory. Unfortunately, the views on offer from the philosophy of action are almost exclusively concerned with and modeled on the actions of individuals. This will be problematic if there are features of individuals influencing the account that are unnecessary for action. And, indeed, with some accounts, this is clearly the case.

On the account of action in Ginet (1990), for example, any action comes with an experience of acting. This is what Ginet calls the 'act-ish phenomenal quality.' This experience-the feeling of what it is like to be the agent of our action-is partially constitutive of the action itself. We cannot act without it. This view, and others that emphasize the phenomenology of action, will be difficult for a proponent of group action to capture. Making the case that groups have any phenomenology at all is something very few have or would maintain. ${ }^{5}$ Even for those willing to accept some kind of group experience, though, it would be difficult to maintain that groups have the experience of agency in particular.

More likely, we should say that the proponent of group action does not need to accommodate this constraint. While having a certain phenomenology may be typical of our actions, further argumentation is needed to show that it accompanies action generally. And even if it were constitutive of our actions, it may not be constitutive of action generally. Given this, I want to consider a more popular account, the Causal Theory of Action (the 'CTA'). This account is plausible, and it can arguably be used to capture group action if we accept certain views within the philosophy of mind. However, we will see that this view ultimately also has elements specific to individuals that groups may not need to satisfy.

\subsection{The CTA, and Attempts to Accommodate It}

The idea behind the CTA is that actions are explained by an agent's motivating reasons for acting, those reasons are either identical with or closely related to the agent's beliefs/desires/intentions, and these mental states explain the agent's action in virtue of causing the action in the right way. For example, when I perform the action of walking towards the refrigerator, this action was done for a reason: I wanted milk. My behavior is intelligible because my desire for milk and my belief that there was milk in the fridge caused me to get up and walk towards the refrigerator.

A version of this account was first given in Davidson (1963), where Davidson famously argued that what distinguishes the reasons for which we act from the reasons we merely have to perform some action is that the reasons for which we act caused us to act. He also identified the agent's reasons with her pro-attitudes, or a belief/desire pair: the desire for some end and a means-end belief that this action will be a means of achieving the desired end. Since Davidson, many different versions of the

\footnotetext{
4 Velasquez $(1983,2003)$ grants that corporations exist and that their behavior is constituted by the actions of their employees. However, they will not satisfy the conditions needed to act. More recently, Ludwig (2016, 2017a) includes groups in his ontology, but he argues that the sentences that we use about their conduct should be analyzed in a way that does not involve positing the group itself as performing actions.

5 Silver (2019) suggests that proponents of corporate agency should not rule out corporate phenomenology, and Schwitzgebel (2015) thinks group consciousness is instantiated if materialism is true.
} 
CTA have been given. To show what they have in common, we can step back and recognize the following schema for the CTA, given in a volume on the CTA by Jesús Aguilar and Andrei Buckareff:

(CTA) Any behavioral event $A$ of an agent $S$ is an action if and only if $S$ 's $A$-ing is caused in the right way and causally explained by some appropriate nonactional mental event(s) that mediate or constitute $S$ 's reasons for $A$-ing. (2010:1)

With these minimal commitments, this view is likely to be endorsed by any of its proponents, and there are many. The view so-put is far from uncontroversial, but though objections to the CTA persist, it is still widely regarded as the standard account of action. Given this, we may ask: Can some version of this account be extended to the case of group behavior?

The primary difficulty of adopting this view in the case of groups is that it is committed to the agent's having certain mental states that cause their behavior. ${ }^{6}$ We would need to find a way of saying that groups as agents have mental states such as beliefs, desires, and intentions that play this role, and it's difficult to imagine that any group would be able to satisfy this. Still, several responses are available.

One response to this challenge is to say that this account also smuggles in elements only necessary for individual action, just as Ginet's account did. I think this is the right response; however, one is hard-pressed to find it in the literature. ${ }^{7}$ The typical response, given by those anxious to argue for group and corporate responsibility, is that groups can instantiate mental states that play the right role in causing group behavior after all. Given this, let's take a moment to consider how this idea often goes and why it has proven so difficult to convince opponents.

The typical route to group mentality involves accepting functionalism in the philosophy of mind. ${ }^{8}$ On this view, fulfilling the function of a mental state-playing the causal role played by that mental state-is constitutive of or sufficient for instantiating that state. So, if an entity exhibits some state that has the typical causal profile that a state of belief would (e.g., behaving as if something is true), then the entity can be argued to be in a state of belief. Clark (1994), Weaver (1998), Hess (2014) each accept functionalism and make the case that corporations have beliefs and desires on a

${ }^{6}$ This commitment is likely to be shared even by those who reject the CTA. Volitionists, for example, both reject the CTA and maintain that actions are (or are in part) mental events (e.g., O’Shaughnessy, 1973; McCann, 1974).

7 Part of the reason for this is just that most of the literature on this topic (of group mentality/agency) is spent characterizing the nature of the mental states of individuals as they work together. Margaret Gilbert, Michael Bratman, Raimo Tuomela, John Searle, Abraham Roth, Kirk Ludwig, and a number of others spend a significant amount of work on group action focused on questions concerning the content of the intentions individuals have when collaborating, or whether this involves engaging in a distinctive type of intention or mode of intending, or whether this involves sharing mental states. Little of this work is concerned with arguing that groups themselves instantiate particular mental states, and most of these authors explicitly doubt this. The few exceptions still involve analyzing group mental states in terms of the mental states of their members, not of reifying group mentality (e.g., Gilbert, 1987; Tuomela, 1992). That said, Gilbert (2002) suggests about beliefs that there may be features unique to individual or group belief such that a group's being in a state that fails to have these features may be insufficient to show that the group is not legitimately believing.

8 Though I focus on functionalism, there may be other ways for arguing for group mentality. Philip Pettit has argued in that groups can make decisions in ways that separate their judgments from the judgments of their members (2001, 2007, 2010, 2017). He takes groups to be capable of deciding on the basis of the group's reasons and of holding themselves as answerable to those reasons. Insofar as this conduct requires or is indicative of certain mental states, Pettit takes it to show that groups have mental states such as beliefs, desires, and intentions. This work is compelling; however, opponents offer alternative explanations that do not advert to group mental states. It could be argued that the members think it is best to act as if the group comes to decisions, forms intentions, and executes them in a rational manner, but that the group itself does not actually instantiate these states. The members may be committed to the group and to its appearing like a rational agent (and held to that standard). Still, wishing doesn't make it so. Velasquez (2003) and Roth (2017) both discuss this way of explaining individual behavior within groups. 
Kenneth Silver

functionalist picture. ${ }^{9}$ Similarly, Copp (2006) and Björnsson and Hess (2017) are even more explicit about adopting functionalism to capture group and corporate beliefs/intentions and reactive attitudes, respectively.

Despite these thorough efforts, accepting functionalism is a steep cost. It's a substantial commitment about the nature of mentality. This is also just the kind of cost that opponents of group action will be unwilling to pay. Opponents tend to dismiss functionalism (and group action) precisely because they think having mental states involves more than merely fulfilling functional roles. What's more, they take this to be obvious. Velasquez admits that corporate agency could be saved by adopting functionalism, but leaves the rejection of it to an endnote (2003:endnote 40). Ludwig dismisses functionalism and its application to corporations just as swiftly and also in an endnote (2017b:endnote 8). Similarly, Rönnegard (2013:85-86) objects to the use of the deflationary approaches to the mind to secure corporate agency. More anecdotally, in conversation I consistently encounter the claim that accepting functionalism lowers the bar for mentality so far that groups count as having mental states not worth the name.

Stepping back, this reaction should be unsurprising. Historically, the most compelling cases against functionalism are cases involving groups. In Block's (1978) influential thought experiment, we are told to imagine the citizens of the Chinese nation organized to instantiate the same pattern of interactions as the firing of neurons in an individual. Block took it as prima facie intuitive that the group does not instantiate qualitative states (e.g., pain), ${ }^{10}$ and many people agree. No wonder, then, that opponents are not convinced. They are being asked to accept functionalism in cases very similar to those that led them to be skeptical of it in the first place.

To resolve this debate, one way to proceed would be to dig in and attempt to more persuasively argue for functionalism. It is arguably the dominant view within the philosophy of mind after all. Though tempting, I think we should resist this route. It's challenging ${ }^{11}$ and unnecessary. We can revise our account of action in a way that does not compel us to take a stance about the nature of mental states. ${ }^{12}$ Moreover, we should. It's not that we are merely able to accept a view of action that allows us to side-step this debate. Engaging in this debate in a sense misses the point. Rather than focusing on the mental, the right account of action emphasizes the role of reasons instead. I will argue that mental states are important for action insofar as they facilitate this role, and that groups may not require mental states to be sensitive to their reasons.

\subsection{The Role of Mental States in the CTA}

\footnotetext{
${ }^{9}$ Specifically, they each appear to accept something like the view advocated for by Daniel Dennett in The Intentional Stance. Tollefsen (2002) even argues for corporate intentionality directly via taking on the intentional stance. However, this is a very deflationary brand of functionalism. For Dennett, we should ascribe beliefs and desires to things to the degree to which it aids us in providing helpful explanations and predictions of the thing's conduct, but, in a sense, there are no actual beliefs and desires that creatures may or might not have. Things 'have' these states to the degree to which it is helpful to ascribe those states. This is an extreme view in the philosophy of mind, so it would be unfortunate if proponents of group action had to accept it (unless it's true).

${ }^{10}$ It is important to note that this is an intuition about qualia, or about a group's having some phenomenology, but nearly all of the proponents of group action will readily agree that groups lack phenomenology. Of course, people have used this case more generally to argue that groups with functionally equivalent states would also fail to have mental states.

${ }^{11}$ We would also need to argue that groups instantiate occurrent mental states that non-deviantly cause their behavior.

${ }^{12}$ Cf. Velasquez and Rönnegard: "....it is arguable that if one holds that organizations can be morally responsible for what they do, then one must hold a functionalist theory of mind” ([emphasis added], 2017:128).
} 
The Causal Theory of Action is widely held, and it is not obviously made to capture only the actions of individuals. Nevertheless, it does this by how it privileges the role of mental states. Consider again the role they play in the CTA. In Davidson's original version, our beliefs and desires are the reasons for which we act. These reasons explain our behavior in virtue of causing it, because they are identical with the mental states that cause it.

In the more recent schema, what remains of this idea is that our mental states cause our behavior, and the reasons that explain our behavior are connected to these mental states in some way. Acting for reasons is still understood causally, but philosophers may disagree about whether the reasons themselves do the causing (as mental states) or if instead our reasons are apprehended or constituted by our mental states, which then go on to do the causing. ${ }^{13}$ Distinguishing our reasons from our mental states in this way is crucial, because it creates space to suggest that the role being played by our mental states could be played by something else. ${ }^{14}$ Crucially, it privileges the role of reasons.

What is central to the concept of action is not that we have mental states that cause our actions; rather, it is that our actions are sensitive to reasons in the right way. A prominent idea from Anscombe (1957) is that action is answerable to reason. It is debatable whether every intentional action is done for a reason, ${ }^{15}$ but a very common assumption in the philosophy of action is that if something is an action, then it is at least appropriate to expect that the behavior was done for reasons or could be explained in terms of reasons. We can easily recognize this idea in the CTA, which takes for granted that actions are explained by reasons.

As far as I can tell, there is no reason for proponents or opponents of group action to object to this idea. After all, everybody knows that there is more to action than a behavior's being caused by mental states. That behavior has to be caused in the right way. Though the problem of deviant causal chains looms large, one thing we can say about this is that the right way will involve the agent's being appropriately responsive to her reasons. The current debate may be focused on whether groups have mental states; however, mental states may only matter to action insofar they allow the agent to respond to reasons and to explain her actions in terms of them.

Something close to this idea has been internalized in certain ways in the very recent writings of certain proponents of group agency. For example, Pettit (2017) makes central the idea that corporations can be called to justify their conduct, and that they do so in terms of their reasons. Björnsson and Hess (op. cit.) also recognize that there is something more fundamental to agency than an agent's having certain mental states. Although they do accept functionalism on the way to arguing for corporate reactive attitudes, Björnsson and Hess go out of their way to say that it does not matter whether corporations have 'full blown' mental states; instead, what matters is "...that corporations can possess those aspects of beliefs, desires, and intentions that are necessary for rational agency" (fn.14). This does not tell us what aspects are necessary for rational agency. Regardless, it paves the way for the idea that groups may not need mental states at all in order to act.

\footnotetext{
13 And, in fact, they do. Davis (2005) and Setiya (2009) argue that reasons must be distinguished from mental states in order to successfully defend a causal theory, whereas Sandis (2009) argues that distinguishing reasons from psychological motivation is necessary but involves forfeiting a causal view. If the heart of a causal theory of action is that actions are understood in terms of their causes, then we should side with Davis and Setiya; but if what is crucial to a causal theory is that actions are caused by reasons, then Sandis is right. I think this debate is inconsequential, as what is important is captured by both - an understanding of the true relation between an action and the reasons for which it is performed.

14 As we will see below, this may be true even if reasons are identical to mental states in us.

15 Alvarez (2009), for example, argues against this popular claim.
} 
Kenneth Silver

Penultimate version

Though creatures like us may need mental states to act, it seems far from a conceptual truth that actions are caused by certain mental states. ${ }^{16,17}$ The conceptual truth that I have been pushing is that actions are explained by reasons (or up for being so-explained). The manner of explanation may always be causal, but it seems possible in principle that entities without mental states could perform actions (and possibly be responsible for them). What will matter will be that the behavior of these entities is rendered intelligible by referencing reasons, and that their behavior is generally sensitive in the right way to those reasons. This suggests the following, even more abstracted version of the CTA:

CTA*: Any behavioral event $A$ of an entity ${ }^{18} S$ is an action if and only if $S$ ' $A$-ing is caused in the right way and causally explained by some appropriate nonactional internal event(s) that mediate or constitute $S$ 's reasons for A-ing.

Moving from speaking in terms of 'mental' events to merely 'internal' events may seem to make little difference. Even if not a conceptual truth, we may think that it is an empirical fact that mental states are the only items that can actually play this role. I will put pressure on this thought in section (2.1), but for now we only need to appreciate how this opens the door for thinking that the behavior of groups might count as action even if we think functionalism about the mind is false or that groups do not instantiate states functionally equivalent to beliefs and desires. This is important to do, because our intuitions concerning group action might be stronger than our intuitions concerning functionalism. If it turns out that functionalism is false (which it might be), or that groups do not instantiate functionally equivalent states (and they might not), I think that we nevertheless should hold on to the idea that groups act. This is something that CTA* allows us to do.

Suppose that functionalism about the mind is false. So, the fact that groups instantiate states functionally equivalent to beliefs, desires, and intentions does not demonstrate that they bave these mental states. Still, we may think that they have states that are capable of playing the same roles that our mental states play within us. Even if these states are not beliefs or desires, they would still be able to play the role of mediating the group's reasons. In this case, the group would count as acting, though it would not have mental states.

We can go even further. Suppose that groups lack states that are even functionally equivalent to beliefs/desires/intentions. Opponents may deny that attempts to show that group have functionally equivalent states succeed, claiming they involve more hand-waving than thorough functional characterization. On my view, groups will not even need genuinely functionally equivalent states. If what is necessary for action are states merely capable of mediating or constituting the agent's reasons for acting, then perhaps groups have states that can play this role, even if not all of the roles played by our mental states. ${ }^{19}$

\footnotetext{
16 Though, it may be that part of what conceptually defines these mental states is that they play this role in the etiology of our actions. For example, on certain dispositionalist accounts of desire, what it is to desire some end will be to be disposed to act so as to achieve that end. So, it may be that we would not have mental states (or at least beliefs/desires/intentions) if they could not play this role. Accepting this kind of account though would be to accept a kind of functionalism that would allow for group mentality after all.

17 Thanks to Neil Sinhababu for suggesting that this be put in terms of the concept of action.

18 This is also a change from CTA, which presupposes that $S$ is an agent, and so it classifies which behavioral events of agents count as actions. We are simply trying to find out which events count as actions, where agency as a notion may be understood afterwards in terms of which entities act. This may not be the right way to think of agency ultimately; the concept of agency may play a more fundamental role than I allow. However, if we can capture action and, more importantly, action for which we are responsible, then I am not sure what role that would be. If there is such a role, then it may still be that groups could satisfy it and be agents, but it would be a different task to show that.

${ }^{19}$ I take this to be what Björnsson and Hess mean when they speak of corporations as instantiating 'rational equivalents' of beliefs/desires, even if not full-blown beliefs/desires (op. cit:278). What is crucial for them is that corporations instantiate states necessary for rational or moral agency.
} 
Kenneth Silver

Penultimate version

Whereas how one feels about this debate concerning group action often tracks whether one is willing to accept functionalism in the philosophy of mind, I am suggesting that group action is possible regardless. We may have good reasons for not being functionalists. We may even deny that groups instantiate states functionally equivalent to our mental states. Nevertheless, we can affirm group action.

\subsection{Are the Actions of $C T A^{*}$ Intentional?}

To clarify the scope of the account, we should take a moment to consider what sort of action is picked out by CTA*. Though the original CTA in its refined form doesn't mention intentions, it is typically thought of as a view of intentional action. As CTA* is almost identical, should we also take it to be a theory of intentional action, or does it capture some broader notion of action? If the former, it will admittedly seem odd if groups can satisfy the account without ever having any intentions. But, if the latter, we will worry that the account is too broad. Groups will count as performing 'actions' barely worth the name, or actions of the sort performed by termites and other barely-minded (and clearly non-responsible) creatures.

There is a way of understanding intentional action that does seem necessarily mental. The socalled 'Simple View' of intentional action is that in all cases intentionally A-ing entails an intention to A (e.g., McCann, 1987). Even those that deny the Simple View typically still think there is some intention in the offing (an intention to try to A, perhaps) (Bratman, 1984). And even apart from this debate, there is a sense of speaking of intentional conduct where it feels like we are grasping for something epistemic - the action was done purposefully or with some other sense that the agent knew what they were doing. So understood, it is going to be hard to believe that groups without minds can act intentionally.

Now, there are ways to directly respond. Bratman (2017) has recently argued that groups can have intentions without having minds, drawing in part from Velleman's (1997) discussion of how we can have intentions that are themselves not mental states. So, perhaps groups could act intentionally without having minds. Alternatively, Hakli (2007) has argued that groups can have epistemic states of knowledge without having a mental state of belief, which could provide a way of showing how groups can act knowingly without minds. Rather than pursue these suggestions, though, I will suggest that CTA* captures what is essential to intentional action apart from any commitment to mental states.

In a recent paper on this topic, Santiago Amaya writes,

... intentional action necessarily involves succeeding at something. At the very least, by doing something intentionally you succeed at doing that thing. Notice that this is not true about other forms of activity. A sneeze, for example, might help achieve all sorts of things. But sneezing is not normally something at which one succeeds. (2018:1776-7)

Amaya says this in the course of arguing for a version of the Simple View. That is, for him intentionally A-ing does entail intending to A. Fundamentally, though, he thinks intentions are necessary because they are the standard of evaluation by which an action is measured as having succeeded or failed. If an agent B'd rather than A'd but intended in that instance to A, then we will know that they have failed in some measure. This opens up space to see how agents could act intentionally without mentioning intentions. What is critical is that there is some standard with which we can judge that the agent has succeeded or failed.

Consider my waving to you. The explanation of my waving was that I wanted to greet you. This was the reason I waved, and this reason motivated my conduct. But now imagine that you take offense at my waving. Perhaps I promised I wouldn't wave to you anymore but forgot. Offending you 
is something that I do unintentionally. In this case, the reason for my action is that I wanted to greet you, and I succeed at greeting you insofar as my conduct matches the content of this reason and was motivated by it. We can tell that offending you is an unintentional action, however, because it's something that I do that I don't have reason to do, or no consideration motivates me to offend you.

It may be that for creatures like us, we need states of intentions to appropriately set the standards for our conduct, to make our actions reasonable, and to motivate us to act. But plausibly what is doing the work here is whether conduct is done in light of one's reasons. If this is true, then perhaps this is something that groups can do without intentions. We may still hesitate about calling group conduct 'intentional' if we are going to deny that they have intentions, but their behavior will still include what is most important to us about intentional conduct. They can be motivated on the basis of reasons and succeed or fail depending on whether their subsequent conduct matches the content of (and appropriately follows from) those reasons.

This does not quite answer the above worry about whether this conception of action is too general. We have not said why this makes the conduct of certain groups more like our own, and why the same is not true of termites and other beings. In fairness, answering the question of what separates our agency from that of beings like termites is one of the most challenging questions within philosophy of action. If there is a substantive answer to it, however, I believe it would come down to how we think about what it is to act on the basis of reasons, and our understanding of the reasons at issue in CTA*. So, it is to this task that I now turn.

\section{Group Reasons}

For groups to act, the behavior of groups must be explicable in terms of reasons, ${ }^{20}$ and there must be states capable of mediating those reasons even if they are not mental states. These are not small assumptions. Despite deep disagreements in the reasons literature, one item of agreement is that an agent's behavior is explained in terms of her reasons at least partly because of her mental states. This may be because the agent's reasons just are those mental states or because those mental states are required to appreciate those reasons and motivate the agent, but philosophers agree that mental states are a part of the story. If this is right, then groups will not be able to act for reasons without having mental states after all.

In this section, I will challenge the consensus. Group behavior can be explained in terms of reasons even if groups do not themselves have mental states. I will start by getting clear about the kind of reasons essential to explaining action: motivating reasons. Then, I will make the case that the behavior of certain groups is best explained in terms of motivating reasons. Not only is there a prima facie case for this given how we talk, but groups can instantiate states that play the roles that are played by motivating reasons.

\subsection{Motivating Reasons}

Every event happens for some reason insofar as events have causes and can be explained in terms of them. This kind of reason, often referred to as a merely explanatory reason, is not the sense of reason

\footnotetext{
20 The idea is that groups are motivated by reasons to act, not that individuals are motivated by reasons to act as members
} of groups. This latter thought has commanded most of the attention in the literature (e.g., Woodard, 2003, 2017). 
that is connected to action. The reasons essential to action are not picked out post hoc as whatever happened to causally explain a certain behavior.

The reasons we are after must exist before the action; the action is sensitive to these reasons and motivated by them. These are the reasons for which, or on the basis of which, the agent performs the action. They rationalize the agent's actions and make them intelligible, answering why the action was performed. These are motivating reasons, ${ }^{21}$ and it is these reasons that are taken to be referenced in CTA/CTA*.

We began with the intuition that when Amazon acquires Whole Foods it is not unintelligible to us why this occurs. If someone asks, 'Why did Amazon acquire Whole Foods?' there are answers available: 'it was a part of Amazon's strategy to enter the grocery business'; 'the high-end product offerings of Whole Foods are on brand with the product offerings of Amazon'; 'Amazon has the capacity to ramp up the food delivery service (making Whole Foods much more valuable than the price of their acquisition)'. What we are offering here are reasons that we take to have motivated Amazon to make the acquisition. They explain why the acquisition occurred, and they do so in a way that is more than merely causal. These explanations render the acquisition intelligible to us and rationalize Amazon's behavior. Of course, Amazon may not have acquired Whole Foods for these particular reasons. There may have been other reasons. ${ }^{22}$ Nevertheless, Amazon's behavior is of the sort we take to be explicable in terms of reasons, even if we are not entirely sure what they are.

These rationalizing explanations are ubiquitous when considering group behavior. Apple repurchased shares because the price was low relative to estimates of the firm's value. The Supreme Court overruled the lower court because the lower court's verdict was mistaken. The football team ran the ball because doing so avoided stopping the game clock. Prima facie, these explanations advert to reasons that motivated the group to behave as it did. They make it rational for the group to do as it does. So, why would we doubt that groups have motivating reasons?

Standard orthodoxy has it that motivating reasons are or require mental states within the agent, and it's not hard to see why. It seems like our behavior cannot be rationalized without ultimately adverting to certain mental states. Why did I move to the fridge and grab a pitcher containing water? This behavior was rational if I believed that there was water in the fridge or if I wanted whatever I believed to be in the pitcher. Parties to the debate disagree over whether my reason was my belief ${ }^{23}$

\footnotetext{
${ }^{21}$ Motivating reasons are often distinguished from normative reasons, or the reasons that there are for the agent to act that should motivate that agent (rather than the considerations that explain/rationalize the agent's conduct). How to distinguish between motivating and normative reasons is controversial, and I will not address this here. However, we should note two things. First, action is typically taken to be in response to motivating reasons, so we only need to show that groups can be motivated by reasons to show that they act. Second, there is a presumption amongst group agency theorists that groups also have normative reasons. Goodpaster (1979) and Donaldson (1982) maintain that corporations can be sensitive to moral considerations, and these may be best understood in terms of normative reasons. Further, Pettit's (2017) emphasis is on the answerability of corporate agents, that their conduct is not merely explicable in terms of reasons but that it is justified by adverting to them. And what is often taken to be distinctive of normative reasons is their role in justifying conduct (Smith, 1994:95-6). Finally, most proponents of corporate agency would take corporations to be capable of having values, which we may take to provide a source of their normative reasons.

22 If groups do not have mental states, then a class of reasons that we often mention will be unavailable. We may say that Amazon acquired Whole Foods because it wanted to be in the grocery business, but this would be false strictly speaking. Amazon would not want anything, and so its desires could not be among the reasons for it to act.

${ }^{23}$ Davidson (1963) and Smith (op. cit.) both maintain that reasons are psychological states including beliefs and desires.
} 
Kenneth Silver

that there was water in the fridge or the fact ${ }^{24}$ that there was water in the fridge. ${ }^{25}$ Whatever the reason is, I will not be able to behave in light of it without beliefs about it.

My conduct will not be intelligible, nor rational, if I did not have any beliefs about the fridge or what was in it. Certain considerations bear on my behaving a certain way, and I must be able to behave in light of them for this behavior to be explained by or rationalized by those considerations. The only way that I can do this, however, is with mental states such as beliefs, desires, and intentions. These states are about reasons. They focus my attention on those considerations that bear on my action, and they help to guide my conduct. As we act, we form beliefs about considerations that bear on our behavior, and we form intentions concerning how to behave. With nothing else within us able to play these roles, it is necessary for us to have mental states in order to act. But groups don't need mental states themselves to play these roles, because they have us as members to do it for them.

Consider again the case of Amazon's acquisition. Amazon behaves in a certain way that is constituted by what is done by the employees. Given this, the behavior of Amazon will be motivated if the employees have been motivated. ${ }^{26}$ This alone doesn't tell us whether Amazon's behavior was motivated by the reason offered above: the fact that the acquisition was in line with its strategy. But this is apparent. This is precisely the reason that the employees will give when asked why they engaged in their own behavior surrounding the acquisition.

The analysts went about trying to identify possible acquisition targets because that was in line with the strategy set by management; the directors considered the proposed target in light of the strategy; many employees played roles meant to facilitate Amazon's execution of this strategy. In each case, the member of the corporation acted because of the corporate strategy. While employees at every level may have had their own reasons for complying with their bosses and for doing their jobs, the reason for their job is ultimately that it in some way facilitates the corporate strategy. More colloquially, employees help the corporation to do what it is trying to do. Organizational structure is set-up (often consciously) to facilitate organizational action.

This is true more generally of much group behavior. Members individually represent the content of considerations that bear on the behavior of the group given its commitments. ${ }^{27}$ They form beliefs about what the group needs to do and/or what they need to do as members of the group on the basis of these representations. ${ }^{28}$ This leads them to form intentions and to act so as to constitute

24 See Dancy (2000) and Alvarez (2010). It is worth noting that Dancy takes his views to militate against the causal theory of action (Alvarez is agnostic concerning it). However, Davis (op. cit.), Setiya (op. cit.), and Mantel (2016) each explicitly argue for some version of the CTA against Dancy while granting that motivating reasons might not be mental states.

${ }^{25}$ Alternatively, we might maintain that my reason was a feature of my situation (Beaulieu, 2013) or that my reason was the proposition that there was water in the fridge (Setiya, op. cit: Mantel, 2014,2017; Singh, 2019). On these latter views, motivating reasons are the contents of beliefs. I remain agnostic here concerning the metaphysics of motivating reasons. If it turns out that motivating reasons are mental states in $u s$, then the functionalism that I offer below will amount to suggesting that motivating reasons are functionally equivalent non-mental states in groups.

${ }^{26}$ This contradicts the Humean theory of motivation, according to which agents must have desires in order to be motivated to act. Still, desires may remain a part of the picture. Group action may still require desires on the part of the members, though the group itself will not have to instantiate desires. The desires of the members may not even need to be about the group's action, since the individual members may have separate reasons for playing their part in the organization.

${ }^{27}$ Even if we push back on the idea that the group can have commitments without having mental states, we can imagine a group with no commitments that still acts for reasons. A corporation may lack a business strategy but still furnish a $10 \mathrm{~K}$ to be compliant with the law. This corporation performs an action and does so for a reason.

${ }^{28}$ Can termites? Though it would take us too far afield to settle this issue, I suspect that the difference between our actions and the behavior of termites (and why these groups are more like us) lies here. Whereas termites may react to their environment and may even count as representing their environment and responding to it on the basis of their drives, I doubt that they represent and react not just their environment but to how their behavior in this environment bears on their goals. This is what is needed to count as appreciating and responding to reasons, and it is what I think both we and certain groups can achieve. 
the group's appropriate response. Members of the group can understand the commitments of the group and motivate the group to act accordingly. ${ }^{29}$ Given this, one way of explaining group behavior will be to advert to those reasons that bear on the group's conduct.

We saw that what is needed to satisfy CTA* is for something internal to the group to play the role of mediating the group's motivating reasons and of causing the behavior of the group to be in line with those reasons. These individual members of the group are well-placed to play these roles. The members themselves are internal insofar as they are parts of the group, and so events involving them will count as internal.

One concern with our characterizing events involving the members as internal to the group is that it threatens to undermine appealing to CTA*. The allure of CTA* was that it created conceptual space for action without mental states, but we may well think that the mental states of the members of groups are an important part of the story. ${ }^{30}$ We may even take those mental states to also count as internal to the group agent. ${ }^{31}$ So, group action would be in terms of mental states after all.

The more important point is that this is a picture of group action that does not require the group itself to instantiate mental states (or group mentality). Our first order of business has to be show how groups can act without themselves having mental states, not to vindicate CTA*. Still, we might wonder: If it turns out that mental states are necessary to the story as internal to the acting agent, then couldn't we have just stuck with CTA? The group agent's reasons would be mediated by beliefs and desires after all; it just wouldn't be the group's beliefs and desires.

Despite this concern, I think we are justified in appealing to CTA*. It is not obvious that the mental states of members of a group count as internal to the group agent. How much of the mental lives of employees, even at work, can be appropriated by the firm? Employees do need to be motivated to behave in ways that constitute the group's conduct, but those employees may not be responsible themselves for mediating the group's reasons anyway. We could imagine some software program that intakes the firm's market position and represents which strategy is optimal given the firm's targets. Though employees may need to take in these representations mentally for themselves to get moving, all of the work of mediating the firm's reasons and outputting directives could be done by this managerial software. This would still seem like group action, but it would require CTA* ${ }^{32}$

\footnotetext{
29 This could be true of all members, but it need not be. Only certain members-board members, managers, key decisionmakers - may be guided by the commitments of the group. This appeal to a subset of members is not novel. Tuomela (2004) and Lackey (2016) both distinguish 'operative members' as those with relevant decision-making authority.

${ }^{30}$ Mental states of the agent might involve imagining what states it would be appropriate for the group to be in if the group had mental states. This is related to the idea found in Tollefsen (2008) that even if corporations themselves cannot feel emotions, employees can feel corporate emotions vicariously by considering what emotions it would be appropriate for an agent to feel in the circumstances of the corporation. While this may not be sufficient to show that the corporation itself has emotions (as Tollefsen recognizes), judgments of the appropriateness of mental states may be sufficient for employees to act in such as a way as to play the role that mental states play in action for groups.

31 One way of construing these states as internal would be to argue that these states are immediately accessible to the group. Copp (2006: 198-200) argues that collectives themselves count as having the intentional states that are necessary for intentional action because those states are immediately accessible to the collective for use in deliberation. If, contra Copp, functionalism in false, then we should say that it is sufficient that groups and collectives have intentional states immediately accessible to them even if they do not count as themselves instantiating those states.

32 Abstracting from this, we can imagine designing artificial agents like robots with goals and able to behave on the basis of how that behavior bears on the achievement of those goals. Such agents would likely not be able to appropriately respond to their reasons if they were not in some way representing those reasons. This all suggests that a requirement for action is that the entity at least has internal states that represent the agent's reasons, as these may be necessary to be sensitive and responsive to reasons. If we are disposed to think that such representation constitutes mentality, then this again would not provide a reason for preferring CTA* to something closer to the spirit of CTA. However, someone who denies functionalism about the mind may also be likely to deny this connection between representation and mentality, and so CTA* allows us to remain agnostic concerning the outcome of that debate.
} 
Once we try to create some space between the mental lives of the members and the group itself, however, this may push us to worry that events involving the members of groups are not internal enough. After all, how we can judge when individuals are acting on the group's reasons, rather than their own? Individuals doubtlessly have their own reasons for why they joined the group or continue to act as members. So, there may be concerns about how the reasons of individuals relate to or compete with the reasons provided by the group. Regardless of how we answer this concern, ${ }^{33}$ though, we can trust that the individuals do generally act on the basis of the group's reasons insofar as we can judge that the group's conduct is sensitive to those reasons. To show this, we can leverage work done within the responsibility literature that understands reasons-responsiveness in terms of counterfactual sensitivity to reasons (e.g., Fischer \& Ravizza, 1998).

The exact manner of counterfactual sensitivity necessary to establish genuine reasonsresponsiveness is controversial. One idea, though, is that an agent can be said to be responsive to reasons if it's true that if there had been sufficient reason to do otherwise, then, in a suitably high proportion of worlds in which this reason obtained, the agent would recognize it, act in accordance with it, and do so because of it. This is plausible, and it's not hard to see that what a group does can be sensitive to what reason there is for it to act. ${ }^{34}$

If analysts at Amazon determine that the acquisition of Whole Foods will add value only if it is bought below some specific price, then whether Amazon acquires Whole Foods will be sensitive to the price that can be negotiated. Short of an argument for why group behavior is not sensitive enough to group reasons, we can assert that groups do act 'in light of reasons in that their behavior is counterfactually dependent upon the content of those reasons..$^{35}$ If Amazon had not had a reason to acquire Whole Foods, because the price was too high, then it would not have acquired it. ${ }^{36}$ In this case and many others, the group seems as sensitive to their reasons as we are to ours. If the group's behavior depends upon reasons, then it is appropriate to advert to them in an explanation of group behavior. These reasons concern and rationalize the group's behavior, and so we should think of them as motivating reasons of the group.

\subsection{Functionalism About Reasons}

I have argued that group behavior can be explained in terms of motivating reasons even if the group does not itself have mental states. We speak as if group behavior is best explained by adverting to reasons, and groups instantiate states (involving their members) that play the same roles of motivating group behavior and making that behavior intelligible that our reasons play in us. This amounts to

\footnotetext{
33 A plausible story here, offered by Tuomela (2012), is that members acting under the authority of a group will accept the group's reasons as preempting their own in deliberating about what to do. Members of groups may fail to do this, but they will not be able to fail systematically in this way while maintaining the group's robust sensitivity to its reasons. Further, a group that is taken to be a responsible agent will be such that its members are held to this standard when acting.

34 See Hess (2014a) for an argument that corporations are reasons-responsive.

35 An opponent may doubt that demonstrating a causal relationship between the agent's motivating reasons and its actions is sufficient to show that the agent acted in light of its reasons. However, this skepticism is neither new nor unique to this view. Causal accounts of action generally face the charge that they do not adequately capture the sense in which our actions are guided by our reasons (Frankfurt, 1978).

36 If the corporation had no reason to acquire the target, and the acquisition was entirely pushed through by management, then we should say that it is not a corporate action (although it is something that the corporation does). However, if the corporation had reason to acquire, but failed to have all-things-considered reason to make the acquisition, then we might think (contra French, 1995:56) that this constitutes a case of corporate weakness of will. We lack the space to discuss this further, but a complete account of group agency will involve not only a model for the good cases, but an understanding of cases of akrasia or other ways in which groups can be alienated from their own behavior while still being agents.
} 
Kenneth Silver

accepting a kind of functionalism about motivating reasons. We are saying that the fact that groups instantiate states that play the same role that our reasons play in us is sufficient to show that groups act for reasons. But we moved to talking about reasons to explicitly avoid the debate over functionalism! This might make us worry that I have just traded one functionalism for another. Or, worse, I have moved from a widely held kind of functionalism to a kind of functionalism few accept. Luckily, I think these concerns can be answered. The functionalism on offer is plausible even for opponents of group agency, and it is not all that uncommon.

This section is titled 'functionalism about reasons', and this offers a clear contrast with functionalism about mental states, but this is not entirely accurate. Whereas functionalism about mental states concerns mental states themselves, the functionalism at issue here is not necessarily about which things are motivating reasons ontologically. ${ }^{37}$ Instead, I am proposing functionalism with respect to those states in virtue of which things are reasons, or with respect to the states that motivate the agent on the basis of reasons. Certain kinds of (mental) states in us play the role of apprehending considerations that bear on our behavior and moving us to action, and groups will have other kinds of (organizational) states that play this role. So, this is closer to functionalism concerning the sources of motivation.

Methodologically, functionalism is a natural view in this context. We know that we do recognize considerations that bear on our behavior, and we know that are motivated on that basis to act, but we may be unsure about exactly which states within us play these roles. Even if we are confident that they will be mental states, it is not entirely obvious which ones. We begin, then, with an understanding of the role that these states play and seek out states that can play this role.

Contrast this with how one comes to embrace functionalism about mental states. In that domain, we may begin by fixing on particular states (e.g., beliefs, desires, intentions, etc.), and then considering the role that these states play in our cognitive and behavioral lives. Having done so, we are left to wonder what the relationship is between a particular state and the functional role that it plays. Functionalists about mental states, then, defend the controversial claim that mental states are best analyzed in terms of these functional roles, or that anything that instantiating the particular functional role of a mental state is ipso facto in that mental state, or even that there is nothing to being in a particular state beyond realizing its functional role. ${ }^{38}$

In other words, in the philosophy of mind we often begin with the states, and then we wonder what the relation is between the states and their functions. When it comes to motivating reasons, however, we begin with the function that reasons play, and then we wonder which states in us play this role or facilitate it. This difference becomes apparent when we consider the arguments that have been given against functionalism about the mind. These arguments typically involve considering something that seems to fully satisfy the functional characterization of a particular mental state but that intuitively does not instantiate the state. The nation of China could coordinate in such a way that, as a whole, it satisfies the functional characterization of being in pain, but surely it is not in pain. We

\footnotetext{
37 This depends on the kinds of things that we take motivating reasons to be. If they are propositions, for instance, then reasons for individuals and groups can be the same kinds of things. Individuals and groups will just instantiate different kinds of states that represent those propositions and motivate on the basis of them. However, if motivating reasons are psychological states in us, then we will need to be functionalists about what they are as well. For groups, the reasons themselves will be identified with non-mental states instantiated by groups that play the same role.

38 It's worth acknowledging here that functionalists who subscribe to the Canberra Plan explicitly do not proceed in this way (e.g., Jackson, 1998). Instead, they also can begin by defining theoretical terms in terms of certain roles, and then empirically pursue what, if anything, instantiates these roles. This may allow them to avoid the arguments against functionalism given below. Whether this project succeeds is irrelevant for our purposes, as what matters is just that functionalism about reasons will not proceed in a way that leads to a familiar objection.
} 
Kenneth Silver

know that pain has a certain kind of feeling to it, and it may seem like the nation of distinct people cannot itself have that feeling.

When it comes to motivating reasons, however, it's unclear how this kind of argument would go. If there are considerations that bear on something's behavior, and that behavior is sensitive to the content of those considerations, would we doubt that it acts for reasons? If the nation of China is coordinating in such a way that what it does seems best explained by appealing to reasons, there doesn't seem to be the same kind of epistemic gap that leads us to say: But surely it doesn't behave for reasons! After all, we are assuming that behaving for reasons need not have any accompanying feeling. Behaving for a reason is about responding appropriately to representational content, the behavior is intelligible in light of that content, and this is not a matter of qualia.

Not only does functionalism about reasons avoid the biggest concerns for functionalists about the mind, but it seems in particular to avoid the worries of opponents of group agency. These opponents are first-and-foremost skeptical about the supposed mindedness of group agents, but embracing functionalism about reasons is precisely a way to avoid group mindedness. Opponents of group agency will admit that groups behave in various ways. If there are propositions that bear on the various ways in which they might behave, as there surely are, and their members are capable of representing these propositions and motivating the group to act on the basis of them, then the group can count as behaving in response to motivating reasons, and so acting. There doesn't seem to be any special reason for an opponent of group agency to oppose functionalism about reasons.

Finally, it is worth pointing to several instances in which philosophers seem to already accept this kind of functionalism. As noted, it's not entirely clear which state(s) play the role of motivating the agent in response to her reasons, and there is a lively debate concerning exactly this. Many Humeans argue that motivating reasons are or require desires within the agent (Smith, op. cit.), and some have argued that we can be motivated purely by our beliefs (Parfit, 1997; Dancy, op. cit.). Whereas individuals in these camps still maintain that only one state (or combination of states) motivate the agent, a number of philosophers have suggested that distinct states can play the role of explaining agent motivation in action. Watson (1975), following Plato, argues that the source of one's conduct can stem from either one's motivational system (the desires one has) or one's valuational systems (consisting of one's judgements concerning the good). ${ }^{39}$ Similarly, Nagel (1970) and Korsgaard (1986), following Kant, argue that practical reasoning can be a source of motivation apart from one's desires/passions (or, at least that it has not been ruled out as such). This idea even appears in non-western traditions of philosophy. Kim (2018) argues that Mengzi should be interpreting as positing two distinct sources of moral motivation-one engaging emotions and one involving practical reasoning.

These authors do not portray themselves as accepting functionalism about reasons. And none of them take this role to be played by anything outside of the head. Nevertheless, functionalism about the sources of motivation is what is required. This is a role that is multiply realizable. And these philosophers were only considering what motivation is like for individual agents like us. If actions can be motivated and explained by reasons in more than one way, then we should be open to accepting that behavior is responsive to reasons wherever this role is played.

\footnotetext{
39 The interpretation here is not obvious. Watson endorses two sources of motivation, but it may be that he thinks that although there are two sources from which one gets reasons to act, motivation is still a matter of being moved by desires. He says, "In general form, the desires of Reason are desires for "the Good" and "...to think a thing good is at the same time to desire it...Reason is thus an original spring of action" (207-8). However, this sense of 'desire' may be the weaker sense, according to which all intentional actions performed are desired. What's more important is that one can perform an action because of one's urges or because of one's values. These are both motivating reasons, but they only count as motivating reasons because of the role they play.
} 
Kenneth Silver

Penultimate version

\section{Group Responsibility}

Even if certain groups can act, there is still much to be shown to argue that they can be morally responsible for any of their actions. We would at least have to show that the group has sufficient control over its actions, ${ }^{40}$ and perhaps that these actions are done freely/autonomously. ${ }^{41}$ For certain group agents, I think these challenges can be met. What will concern us here, however, is whether or not our account of group action in some way undermines our attempt to characterize them as possibly responsible. After all, it is plausible to think that certain conditions on moral responsibility involve mental states, and it is not hard to find the suggestion that groups would not be responsible without them.

In her discussion, Tollefsen (2008) suggests that corporations would need to be capable of caring about morality to be responsible agents, and she expresses concern about how to show this, as such care requires emotional capacities. ${ }^{42} \mathrm{Björnsson}$ and Hess (op. cit.) accept that the reactive attitudes such as guilt or indignation are necessary for moral agency on their way to arguing that group agents can be responsible. ${ }^{43}$ Baddorf (2017) argues that corporations and other group agents cannot be accountable because they lack phenomenal consciousness. If emotions, attitudes, or phenomenal consciousness are necessary for moral responsibility, then a group without them will not be responsible even if their conduct satisfies CTA*.

Luckily, there are ways to respond. First, we can recognize that my view is not that groups do not have mental states at all; it is that we do not need to show that they have occurrent beliefs, desires, and intentions that cause their behavior in order to show that they are capable of acting. For all that I have said, certain groups may have beliefs, desires, intentions after all, as well as the emotions and reactive attitudes necessary for moral responsibility. (I still think we are in an especially bad epistemic position to know that they are not phenomenally conscious [Silver, op. cit:261-263].) Or, it could be that groups have certain mental states while lacking others.

Alternatively, we could push on the mentioned accounts of moral responsibility. Not all respectable views of moral responsibility explicitly carry these mental requirements. For Fischer and Ravizza (op. cit.), Wolf (1993), and Nelkin (2011), the ability to be reasons-responsive is all that is necessary for moral responsibility. ${ }^{44}$ Other accounts require not only reason-responsiveness, but the ability and availability to answer with these reasons if asked. Smith (2012) and Hubbs (2013) both emphasize the centrality of answerability, and answerability is one conception of responsibility for Shoemaker (2015). ${ }^{45}$

\footnotetext{
40 Velasquez's original objection to corporate agency was that corporate behavior was controlled by the employees and not the corporation itself (1983). This has been addressed by proponents of group agency (Pettit \& List, op. cit.; Strand, 2012), but a better answer than has been given will involve appealing to extant accounts of control in the agency literature. Further, it will involve a better understanding of the difference between a group's performing some action and a member's performing that action on behalf of the group (or as a proxy for the group). This question of proxy action has been taken up (e.g., Copp, 1979; Ludwig, 2014), and it deserves further reflection.

41 Rönnegard (2013) develops this concern for corporations, and Hess (2014a) offers a defense of corporate freedom/autonomy.

42 Thompson (2018) also appeals to certain emotions to argue that corporations cannot be moral agents. See Jaworska (2007) for arguments that emotions are necessary for caring.

43 Sepinwall (2017) argues that corporations are inappropriate objects of blame precisely because they lack the necessary mental life.

44 These authors don't say, but I believe the account given by Fischer and Ravizza is best interpreted in terms of responsiveness to motivating reasons, whereas Wolf and Nelkin's accounts concern responsiveness to normative reasons. 45 Shoemaker himself maintains that groups like corporations can satisfy this form of responsibility, but not the accountability sense of responsibility as he understands it (Shoemaker, 2019). Still, this is significant. Answerability for
} 
We saw in the last section how group agents may count as reasons-responsive, ${ }^{46}$ and we can also see how to make the case that they can be answerable for their conduct. ${ }^{47}$ To achieve this, we need groups to not only respond to their reasons, but for one of those responses to involve actually giving those reasons as a communicative ability of the group. There is a genuine question about how a group itself could do this, or how it is something that an individual could be capable of doing on behalf of the group. Luckily, there is already a foundation of work towards this end. As noted above, Pettit (2017) argues specifically that groups like corporations can be called to justify their conduct in terms of reasons. As 'conversable agents', groups can answer their reasons via a member acting as a spokesperson authorized to speak on behalf of the group. He says,

The spokespersons who speak in the name of the [group] do not speak just as reporters, as if their job was to take a census on the attitudes of members about any issue they address and then report on what those attitudes seem to be. They speak with the same sort of authority that any one of us assumes when we speak as individuals for ourselves. (22)

Critical for Pettit is that spokespeople do not merely provide evidence for what the group's reason most likely is. They instead have the authority to issue avowals as to the reasons of the group, where their so-saying commits the group to further conduct on that basis. This kind of suggestion requires a package of views concerning avowals, self-knowledge, and the ascription of reasons, a full defense of which goes beyond our efforts here. But the case is there to be made. ${ }^{48}$ It strongly suggests that group agents can answer for their conduct and so be responsible in this sense.

\section{Conclusion}

We began by acknowledging that we frequently speak as if certain groups can do a variety of things. This is vindicated if we can show how these groups count as acting on an independently respectable view of action. The problem, as we saw, is that the widely accepted causal theory of action is typically interpreted as involving behavior that is caused by mental states of the agent, and there is an intractable disagreement about whether groups can instantiate mental states.

To avoid this disagreement, I argued that there are independent reasons for broadening our view of action. What matters for action is not causation by mental states per se; rather, it is that the behavior is caused by internal states that relate in the right way to the agent's motivating reasons. These states facilitate conduct that constitutes a response to those reasons. For individuals like us, our

\footnotetext{
Shoemaker is a high bar, as it involves being able to answer in terms of not only the reasons for why some action was done, but why it was done instead of others. And it is an important sense of responsibility insofar as it may be answerability that is what is foundational for liability in the criminal law (Duff, 2019).

${ }^{46} \mathrm{It}$ is still to be shown that such groups can be sufficiently reasons-responsive to satisfy these accounts of responsibility. (This is what McKenna [2006] challenges, though he grants that they might be reasons-responsive to some degree.) I again think that this challenge can be met, but the broader point is that group agents will not immediately fail to qualify on thes e accounts because they lack mentality.

${ }^{47}$ Answerability is acknowledged even in French's original paper making the case for corporate personhood: "...for someone to legitimately hold someone else responsible for some event there must exist or have existed a responsibility relationship between them such that in regard to the event in question the latter was answerable to the former" (1979:211).

48 On some prominent views, when an agent avows some internal state (such as of being in pain or believing some proposition) she is not relying on a special kind of internal perception, but instead is expressing the state that she is in directly (Bar-On \& Long, 2001; Bar-On, 2004). The authors typically discussing this topic are concerned with how we know our own minds, and of course our question is whether groups can act without them. However, if the same conversations applied to how we have some special knowledge of our own reasons for action, and I think they should, then we could use these accounts to argue that individuals truly can answer about the group's reasons.
} 
Kenneth Silver

Penultimate version

mental states are what play this role, so it was only natural that earlier accounts were put in these terms. However, recognizing this broader view opens up space to appreciate those entities capable of achieving what is central to action without mental states.

Groups in particular seem well-placed to satisfy this broader account without mental states. Why would they need mental states when they are made up of agents who are able to recognize their reasons for them, and to behave so as to constitute the group's response? If functionalists about the mind are right, then these groups may ultimately count as having beliefs and desires that cause their behavior. But suppose the functionalist is wrong. Still, an independently plausible functionalism about reasons suggests that groups can be motivated to act in light of the considerations that bear on their conduct. We saw how such action can not only count as intentional, but that a plausible story is available for how groups could be answerable for it. Thus, groups may act and be responsible for their actions even without minds.

\section{References}

Aguilar, J. \& Buckareff, A. (2010). The CTA: Origins and issues. In J. Aguilar \& A. Buckareff (Eds.), Causing Human Action (pp. 1-26). Cambridge, Mass.: MIT Press.

Alvarez, M. (2009). Acting intentionally and acting for a reason. Inquiry: An Interdisciplinary Journal of Philosophy, 52, 293-305. doi: 10.1080/00201740902917168

Alvarez, M. (2010). Kinds of Reasons: An Essay in the Philosophy of Action. Oxford: Oxford University Press.

Amaya, S. (2018). Two kinds of intentions: A new defense of the Simple View. Philosophical Studies, 175, 1767-1786. doi: 10.1007/s11098-017-0934-1

Anscombe, E. (1957). Intention. Oxford: Basil Blackwell.

Baddorf, M. (2017). Phenomenal consciousness, collective mentality, and collective moral responsibility. Philosophical Studies, 174, 2768-2786. doi: 10.1007/s11098-016-0809-x

Bar-On, D. \& Long, D. C. (2001). Avowals and first-person privilege. Philosophy and Phenomenological Research, 62, 311-335. doi: 10.1111/j.1933-1592.2001.tb00058.x

Bar-On, Dorit. (2004). Speaking my Mind. New York: Oxford University Press.

Beaulieu, Gerald. (2013). Can explanatory reasons be good reasons for action? Metaphilosophy, 44, 440450. doi: $10.1111 /$ meta. 12040

Björnsson, G. \& Hess, K. (2017). Corporate crocodile tears? On the reactive attitudes of corporate agents. Philosophy and Phenomenological Research, 94, 273-298. doi: 10.1111/phpr.12260

Block, N. (1978). Troubles with functionalism. In C. W. Savage (Ed.), Cognition: Issues in the Foundations of Psychology (pp. 261-325). Minneapolis: University of Minnesota Press.

Bratman, M. (1984). Two faces of intention. The Philosophical Review, 93, 375-405. doi: 10.2307/2184542

Bratman, M. (2017). The intentions of a group. In Eric W. Orts \& N. Craig Smith (Eds.) The Moral Responsibility of Firms (pp. 36-52). Oxford: Oxford University Press.

Clark, A. (1994). Beliefs and desires incorporated. The Journal of Philosophy, 91, 404-425. doi: jphil199491815

Copp, D. (1979). Collective actions and secondary actions. American Philosophical Quarterly, 16, 177-186.

Copp, D. (2006). On the agency of certain collective entities: An argument from "normative autonomy." Midwest Studies in Philosophy, 30, 194-221. doi: 10.1111/j.1475-4975.2006.00135.x

Dancy, J. (2000). Practical Reality. Oxford: Oxford University Press. 
Kenneth Silver

Penultimate version

Davidson, D. (1963). Actions, reasons, and causes. The Journal of Philosophy, 60, 685-700. doi: $10.2307 / 2023177$

Davis, W. (2005). Reasons and psychological causes. Philosophical Studies, 122, 51-101. doi: 10.1007/s11098-005-7249-3

Dennett, D. (1987). The Intentional Stance. MIT Press.

Donaldson, T. (1982). Corporations \& Morality. Englewood Cliffs, N.J.: Prentice-Hall.

Dretske, F. (1988). Explaining Behavior. MIT Press.

Duff, R. A. (2019). Moral and criminal responsibility: Answering and refusing to answer. In D. J. Coates \& N. A. Tognazzini, (Eds.), Oxford Studies in Agency and Responsibility (Vol.5). Oxford University Press.

Fischer, J. M. \& Ravizza, M. (1998). Responsibility and Control: A Theory of Moral Responsibility. Cambridge: Cambridge University Press.

Frankfurt, H. (1978). The problem of action. American Philosophical Quarterly, 15, 157-162.

French, P. (1979). The corporation as a moral person. American Philosophical Quarterly, 16, 207-215.

French, P. (1995). Corporate Ethics. Fort Worth, TX: Harcourt Brace College Publishers.

Gilbert, M. (1987). Modelling collective belief. Synthese, 73, 185-204. doi: 10.1007/BF00485446

Giblert, M. (2002). Belief and acceptance as features of groups. Protosociology, 16, 35-69. doi: $10.5840 /$ protosociology20021620

Ginet, C. (1990). On Action. Cambridge University Press.

Goodpaster, K. (1979). Morality and organizations. In T. Donaldson \& P. Werhane (Eds.) Ethical Issues in Business. Englewood Cliffs, N.J.: Prentice-Hall.

Hakli, R. (2007). On the possibility of group knowledge without belief. Social Epistemology, 21, 249-266. doi: $10.1080 / 02691720701685581$

Hess, K. (2014). Because they can: The basis for the moral obligations of (certain) collectives. Midwest Studies in Philosophy, 38, 203-221. doi: 10.1111/misp.12024

Hess, K. (2014a). The free will of corporations (and other collectives). Philosophical Studies, 168, 241260. doi: 10.1007/s11098-013-0128-4

Hubbs, G. (2013). Answerability without answers. Journal of Ethics and Social Philosophy, 7(3), 1-15. doi: 10.26556/jesp.v7i3.74

Jackson, F. (1998). From Metaphysics to Ethics. Oxford University Press.

Jaworska, A. (2007). Caring and full moral standing. Ethics, 117, 460-497. doi: 10.1086/512780

Kim, M. (2018). Emotion and judgment: Two sources of moral motivation in Mengzi. Dao: A Journal of Comparative Philosophy, 17, 51-80. doi: 10.1007/s11712-017-9597-z

Korman, D. (2020). The metaphysics of establishments. Australasian Journal of Philosophy, 98, 434-448. doi: 10.1080/00048402.2019.1622140

Korsgaard, C. (1986). Skepticism about practical reason. The Journal of Philosophy, 83, 5-25. doi: jphil198683183

Lackey, J. (2016). What is justified group belief? The Philosophical Review, 125, 341-396. doi: 10.1215/00318108-3516946

Ludwig, K. (2014). Proxy agency in collective action. Noûs, 48, 75-105. doi: 10.1111/nous.12013

Ludwig, K. (2016). From Individual to Plural Agency: Collective Action I. Oxford University Press.

Ludwig, K. (2017a). From Plural to Institutional Agency: Collective Agency II. Oxford University Press.

Ludwig, K. (2017b). Do corporations have minds of their own? Philosophical Psychology, 30, 260-301. doi: 10.1080/09515089.2017.1295636

Mantel, S. (2014). No reason for identity: on the relation between motivating and normative reasons. Philosophical Explorations, 17, 49-62. doi: 10.1080/13869795.2013.815261 
Kenneth Silver

Mantel, S. (2016). How to be psychologist about motivating but not about normative reasons. Grazer Philosophische Studien, 93, 80-105. doi: 10.1163/18756735-09301005

Mantel, S. (2017). Worldly reasons: An ontological inquiry into motivating considerations and normative reasons. Pacific Philosophical Quarterly, 98, 5-28. doi: 10.1111/papq.12094

McCann, H. (1974). Volition and basic action. Philosophical Review, 83, 451-473. doi: 10.2307/2183915

McCann, H. (1987). Rationality and the range of intention. Midwest Studies in Philosophy, 10, 191-211. doi: 10.1111/j.1475-4975.1987.tb00540.x

McKenna, M. (2006). Collective responsibility and an agent meaning theory. Midwest Studies in Philosophy, 30, 16-34. doi: 10.1111/j.1475-4975.2006.00126.x

Nagel, T. (1970). The Possibility of Altruism. Oxford: Oxford University Press.

Nelkin, D. (2011). Making Sense of Freedom and Responsibility. Oxford University Press.

O'Shaughnessy, B. (1973). Trying (as the mental "pineal gland”). Journal of Philosophy, 70, 365-386.

Parfit, D. (1997). Reasons and motivation. Aristotelian Society Supplementary Volume, 71, 99-130. doi: 10.1111/1467-8349.00021

Parrott, M. (2015). Expressing first-person authority. Philosophical Studies, 172, 2215-2237. doi: $10.1007 / \mathrm{s} 11098-014-0406-9$

Pettit, P. (2001). Deliberative democracy and the discursive dilemma. Noûs, 35, 268-299. doi: 10.1111/0029-4624.35.s1.11

Pettit, P. (2007). Responsibility incorporated. Ethics, 117, 171-201. doi: 10.1086/510695

Pettit, P. (2010). Groups with minds of their own. In A. Goldman \& D. Whitcomb (Eds.), Social Epistemology: Essential Readings (pp. 167-193). Oxford University Press.

Pettit, P. (2017). The conversable, responsible corporation. In E. W. Orts \& N. C. Smith (Eds.) The Moral Responsibility of Firms (pp. 15-35). Oxford: Oxford University Press.

Pettit, P. \& List, C. (2011). Group Agency: The Possibility, Design, and Status of Corporate Agents. Oxford University Press.

Ritchie, K. (2013). What are groups? Philosophical Studies, 166, 257-272. doi: 10.1007/s11098-012-00305

Roth, A. (2017. Shared agency. The Stanford Encyclopedia of Philosophy, E. N. Zalta (Ed.), URL = $<$ https://plato.stanford.edu/archives/sum2017/entries/shared-agency/>.

Rovane, C. (1998). The Bounds of Agency: An Essay in Revisionary Metaphysics. Princeton University Press.

Sandis, C. (2009). Hume and the debate on 'motivating reasons.' In C. Pigden (Ed.), Hume on Motivation and Virtue (pp. 142-154). Palgrave-Macmillan.

Schwitzgebel, E. (2015). If materialism is true, the united states is probably conscious. Philosophical Studies, 172, 1697-1721. doi: 10.1007/s11098-014-0387-8

Sepinwall, A. (2017). Blame, emotion, and the corporation. In E. W. Orts \& N. C. Smith (Eds.) The Moral Responsibility of Firms (pp. 143-166). Oxford: Oxford University Press.

Setiya, K. (2009). Reasons and causes. European Journal of Philosophy, 19, 129-157. doi: 10.1111/j.14680378.2009.00378.x

Shoemaker, D. (2015). Responsibility from the Margins. Oxford: Oxford University Press.

Shoemaker, D. (2019). Blameworthy but unblameable: A paradox of corporate responsibility. Georgetown Journal of Law \& Public Policy, 17(Special Issue), 897-918.

Singh, K. (2019). Acting and believing under the guise of normative reasons. Philosophy and Phenomenological Research, 99, 409-430. doi: 10.1111/phpr.12497

Silver, K. (2019). Can a corporation be worthy of moral consideration? Journal of Business Ethics, 159, 253-265. doi: 10.1007/s10551-018-3787-4

Smith, A. (2012). Attributability, answerability, and accountability: In defense of a unified account. Ethics, 122, 575-589. doi: 10.1086/664752 
Kenneth Silver

Penultimate version

Smith, M. (1994). The Moral Problem. Oxford: Blackwell.

Strand, A. (2012). Group agency, responsibility, and control. Philosophy of the Social Sciences, 43, 201-224. doi: $10.1177 / 0048393111435527$

Thompson, C. (2018). The moral agency of group agents. Erkenntnis, 83, 517-538. doi: $10.1007 / \mathrm{s} 10670-017-9901-7$

Tollefsen, D. (2002). Organizations as true believers. Journal of Social Philosophy, 33, 395-410. doi: $10.1111 / 0047-2786.00149$

Tollefsen, D. (2008). Affectivity, moral agency, and corporate-human relations. APA Newsletter on Philosophy and Law, 7(2), 9-13.

Tuomela, R. (1989). Collective action, supervenience, and constitution. Synthese, 80, 243-266. doi: $10.1007 / \mathrm{BF} 00869486$

Tuomela, R. (1992). Group beliefs. Synthese, 91, 285-318. doi: 10.1007/bf00413570

Tuomela, R. (2004). Group knowledge analyzed. Episteme, 1, 109-127. doi: 103366/epi.2004.1.2.109

Tuomela, R. (2012). Group reasons. Philosophical Issues, 22, 402-418. doi: 10.1111/j.15336077.2012.00237.x

Uzquiano, G. (2004). The Supreme Court and the Supreme Court justices: A metaphysical puzzle. Noûs, 38, 135-153. doi: 10.1111/j.1468.2004.00465.x

Velasquez, M. (1983). Why corporations are not morally responsible for anything they do. Business \& Professional Ethics Journal, 2(3), 1-18. doi: 10.5840/bpej19832349

Velasquez, M. (2003). Debunking corporate moral responsibility. Business Ethics Quarterly, 13, 531-562. doi: $10.5840 /$ beq200313436

Velasquez, M. \& Rönnegard, D. (2017). On (not) attributing moral responsibility to organizations. In E. W. Orts \& N. C. Smith (Eds.) The Moral Responsibility of Firms (pp. 123-142). Oxford: Oxford University Press.

Velleman, J. D. (1997). How to share an intention. Philosophy and Phenomenological Research, 57, 29-50. doi: $10.2307 / 2953776$

Watson, G. (1975). Free agency. Journal of Philosophy, 72, 205-220. doi: 10.2307/2024703

Weaver, W. (1998). Corporations as intentional systems. Journal of Business Ethics, 17, 87-97. doi: 10.1023/A:1017920119864

Wolf, S. (1993). Freedom Within Reason. Oxford University Press.

Woodard, C. (2003). Group-based reasons for action. Ethical Theory and Moral Practice, 6(2), 215-229. doi: $10.1023 / \mathrm{A}: 1024458623591$

Woodard, C. (2017). Three conceptions of group-based reasons. Journal of Social Ontology, 3, 102-127. doi: 10.1515/jso-2016-0006 